\title{
PROPRIEDADES MECÂNICAS DE RESINAS POLIMÉRICAS UTILIZADAS NO ACABAMENTO DE COUROS
}

\author{
C. WINTER ${ }^{1}$, G. L. GRANDI ${ }^{1}$, F. R. F. DARSIE ${ }^{1}$, M. E. R. SCHULTZ ${ }^{2}$, M. GUTTERRES ${ }^{1}$ \\ ${ }^{1}$ Universidade Federal do Rio Grande do Sul, Departamento de Engenharia Química, \\ Laboratório de Estudos em Couro e Meio Ambiente (LACOURO) \\ ${ }^{2}$ Instituto Federal de Educação, Ciência e Tecnologia Sul-Rio-Grandense (IFSUL) \\ E-mail para contato: \{crisw, mariliz\}@enq.ufrgs.br
}

\begin{abstract}
RESUMO - Artigos de couro estão associados com tendências de moda e sofisticação. No seu processamento, a fase de acabamento consiste de um conjunto de operações e tratamentos, essencialmente de superfície, que conferem suas características finais. Os objetivos são reduzir defeitos visíveis, modificar as propriedades superficiais e melhorar os atributos de uso. Nesta fase final, são aplicadas, dentre outros produtos, resinas, geralmente, poliacrilatos e poliuretanos, que formam filmes de recobrimento protetores sobre o couro. Nesse contexto, este trabalho visa a uma avaliação dos filmes formados com resinas poliméricas comerciais utilizadas industrialmente no acabamento de couros, relacionando a composição destes materiais com a sua resistência mecânica, através de testes de tração. Esses ensaios mostraram que as resinas poliuretânicas apresentam uma maior resistência à tração quando comparadas com resinas acrílicas.
\end{abstract}

\section{INTRODUÇÃO}

O couro é um produto nobre e natural amplamente requisitado por aliar tendências de moda, design e estilo. Apresenta uma variada gama de aplicação, dividida em calçados, vestuário, móveis, estofamentos, acessórios, entre outros, possuindo extrema importância na economia brasileira, tanto pelo volume de exportações como pela geração de empregos.

Em seu processamento, o acabamento, que envolve uma série de tratamentos químicos, físicos e físico-químicos, é a fase final do processo de fabricação de um couro, tendo como objetivo o importante papel de conferir ao produto final propriedades adequadas: melhorar a classificação dos couros sem dar quebra da flor ou flor solta, diminuir defeitos superficiais e riscos, proporcionar brilho, tato agradável, igualização de cor, efeitos de cor, tonalidade, textura e padronagens diversas, e ainda, conservar ou devolver o aspecto natural (Adzet et al., 1985). O acabamento do couro consiste na aplicação sobre sua superfície superior (flor) de várias formulações compostas de misturas (emulsões, dispersões, soluções) de produtos químicos, em sucessões de camadas aplicadas, dependendo do artigo desenvolvido, seguidas ou intercaladas por operações de secagem e operações mecânicas como prensagens, polimentos e batimento em fulão. 
São muitos os tipos de acabamento, entre eles os transparentes, com efeito de cobertura que não transmite a passagem da luz, com efeito fosco, abrilhantado, lixado, com relevos, os que conferem cor, textura, etc. (Santos et al., 2011). Os fatores fundamentais em um acabamento são as características do couro, os produtos empregados e os sistemas operativos. As etapas de aplicação de acabamento são impregnação, aplicação de fundos, coberturas e tops intermediários e finais, além de polimentos, prensagens, gravações, tratamento a vácuo, etc. Os principais produtos empregados são pigmentos, corantes, ligantes, auxiliares e lacas.

Os polímeros são materiais de grande aplicabilidade em vários setores industriais e também empregados no acabamento de couros. A polimerização consiste na transformação química de uma substância de baixo peso molecular, o monômero, em outro de peso molecular elevado, o polímero. As resinas sintéticas são polímeros preparados via processos de polimerização. Ligantes de acabamento utilizam os resultados da copolimerização de diferentes monômeros para a obtenção de propriedades específicas (Gratacos et al., 1962).

Os solventes são usados para diluir formadores de filmes altamente poliméricos como a nitrocelulose. Devem ser suficientemente estáveis para a formação de um bom filme, quando depositado sobre superfícies, e com uma relação de evaporação suficientemente rápida para não proporcionar defeitos. Exemplos dos solventes mais utilizados: isopropanol, etilglicol, etanol e butilglicol, os quais funcionam como agentes de umectação (Adzet et al., 1985).

A técnica de polimerização em emulsão aquosa possui vantagens devido às questões ambientais e também pelo procedimento mais fácil de aplicação. Nanocompósitos baseados em silicatos poliméricos (Yilmaz, 2011) são uma alternativa para melhorar as propriedades dos revestimentos à base de água. Resinas e tops uretânicos isentos de solventes, além de suas propriedades, vêm ao encontro da preocupação com os problemas de poluição ambiental (Amorin \& Melillo, 1989).

A busca por materiais baseados em constituintes obtidos de fontes naturais tem se tornado de grande importância. Compósitos naturais possuem boas propriedades mecânicas (Barbosa Jr., 2010) e reduzem a dependência de materiais obtidos a partir de fontes não renováveis, trazendo benefícios econômicos e ambientais.

Muitas resinas são empregadas no acabamento de couros para formar películas, filmes ou camadas de cobertura, pois servem para proteger o couro contra danos, aumentam sua estabilidade quando em contato com umidade e dão aparência, propriedades e efeitos de interesse. As resinas são substâncias constituídas de partículas de material polimérico, regularmente distribuídas em água, na forma de gotículas muito finas. Dentre as resinas empregadas no acabamento de couros, distinguem-se as de base poliacrilato e poliuretano (Fazano, 1995). De acordo com a resina, obtém-se um tipo diferente de filme, com características distintas.

Poliuretanos possuem destaque em razão da qualidade de resistência (química, à tração e à abrasão) e seu quadro de propriedades facilmente modificável. Apresentam características especiais que resultam em acabamentos mais resistentes e duráveis, com boa aderência ao couro, resistentes ao frio, sólidos à luz, flexíveis e podem ter amplamente modificadas as suas propriedades (Henkel, 1986). Possuem a desvantagem do seu alto custo, mas este pode ser substancialmente reduzido pelo uso de comonômeros acrílicos e vinílicos. 
Resinas acrílicas destacam-se pela sua dureza, retenção de calor e brilho, boa resistência à ação de solventes e ao intemperismo (Fazano, 1995). Acrilatos são muito sólidos à luz, econômicos e, por isso, são empregados com mais frequência. Suas propriedades melhoram significativamente os couros (Pietrucha, 1981). Com a crescente preocupação ambiental e exigências de materiais de acabamento, pesquisas têm se concentrado em materiais solúveis em água, diversificando estudos, como as resinas acrílicas em conjunto com óxido de silício visando à diminuição do uso de emulsificantes e consequentemente poluição ambiental (Jing et al., 2008 a) e sínteses de copolímero (acrilato de butila/ácido acrílico) para aplicação no acabamento, com melhorias na absorção de água (Jing et al., 2008 b).

Os esforços para melhorar o acabamento do couro, especialmente em relação às suas propriedades mecânicas, têm conduzido ao estabelecimento de uma variedade de técnicas e desenvolvimentos, nos quais se procuram combinar as vantagens que oferecem os vários tipos de ligantes (Gratacos et al., 1962). Kozakiewicz (1996) já unia as vantagens de polisiloxanos com poliuretanos com o intuito de melhorias das camadas de acabamento. Os chamados sistemas “compactos" resultam da combinação de resinas para obtenção de melhores resultados com relação aos produtos que vêm sendo aplicados no couro. Com isso, ampliam as possibilidades de atender às especificações e inovações que o setor de acabamento requer.

O controle de qualidade dos couros acabados, além de ser feito por meio de análises subjetivas de tato, lisura, flor solta, cobertura e brilho, é feito principalmente através de ensaios físico-mecânicos. Entre estes ensaios estão análise/condensação de substâncias voláteis não fixadas no couro (fogging test), ensaio de resistência à fricção e à flexão contínua, resistência à tração e alongamento, resistência ao rasgamento e à passagem de água através de flexão da amostra (Penetrômetro Bally) ou não (Penetrômetro Maeser). Ainda, existem testes com o objetivo de analisar adesão, marca d'água, solidez à luz, migração ao PVC, lavagem, etc.

Os ensaios de resistência à tração de uma película consistem na determinação da força necessária para rompê-la. A resistência à tração na ruptura é avaliada pela carga aplicada ao material por unidade de área, no momento da ruptura. A elongação (ou alongamento) é um importante fator na seleção de uma película, uma vez que ela deve ter condições de absorver e dissipar choques mecânicos. Representa o aumento percentual do comprimento da peça sob tração, no momento da ruptura, sendo que alongamentos até $900 \%$ são uma característica dos polímeros, em geral (Mano, 1991). A tenacidade é a medida da capacidade do material absorver energia sem romper.

Neste contexto, o presente trabalho propôs a confecção de filmes, utilizando algumas resinas poliméricas usadas atualmente na indústria, e avaliando-as em relação às propriedades mecânicas de tração, alongamento na ruptura e tenacidade.

\section{MATERIAIS E MÉTODOS}

Para avaliar as propriedades dos produtos de acabamento fornecidos pela indústria química para couro, amostras de resinas poliuretânicas e acrílicas foram cedidas por duas empresas do setor coureiro. Essas resinas foram analisadas e suas propriedades testadas separadamente através da confecção de filmes e realização de testes físico-mecânicos para análise de seu comportamento sob uma força aplicada. 
Paralelamente, foram desenvolvidos filmes compactos com a combinação de duas resinas para estudo de melhorias nas propriedades. Além da separação dos ligantes, de acordo com a sua natureza, acrílica ou poliuretânica, tem-se a divisão do seu uso em camada base ou top. As resinas utilizadas como base são mais macias para melhor adesão e podem ser combinadas com pigmentos A camada base proporciona aos couros cor, cobertura, enchimento, solidez e uniformiza a superfície do couro, conferindo a cor desejada. Já as resinas utilizadas como top são responsáveis pelo retoque final da superfície, ou seja, a camada final responsável pelo brilho, toque e algumas propriedades físicas de resistência como abrasão, fricção, flexão, etc., sendo assim, mais dura que a camada base.

\subsection{Materiais e formação dos filmes poliméricos}

Na secagem das resinas (em dispersão aquosa ou solvente orgânico), logo que se afasta o envoltório de água pela evaporação, as diversas partículas de material plástico unem-se umas às outras formando uma película ou aglomerado chamado filme. Assim, o princípio de acabamento de couro com ligantes polimerizados formadores de filme explica-se da seguinte maneira: ao se aplicar na superfície do couro a formulação de cobertura (com pigmentos, resinas, auxiliares, etc.), uma parte considerável da água ou solvente dessa solução é absorvida pela estrutura fibrosa do couro, concentrando-se a solução. Extrai-se, assim, a água da dispersão ligante, precipitando o polímero na forma de película.

Para formação dos filmes foram selecionadas resinas poliuretânicas e acrílicas comerciais aplicadas industrialmente no acabamento. Foi desenvolvida uma metodologia para obtenção dos filmes a partir da análise e cálculo do teor de sólidos das resinas (ABNT 11062 Determinação do teor de sólidos totais) e método da termobalança, e com base na norma ABNT 11033 - Preparação do filme de ligantes. Na elaboração dos filmes sem pigmentos, fixou-se a proporção de $10 \%$ de sólidos totais. Em placas de Petri, cada resina foi diluída em água até atingir a proporção de sólidos determinada, com massa final de 30 g. O material foi colocado em estufa a $60^{\circ} \mathrm{C}$ para secagem da mistura até formação do filme (24 h) (Figura 1).

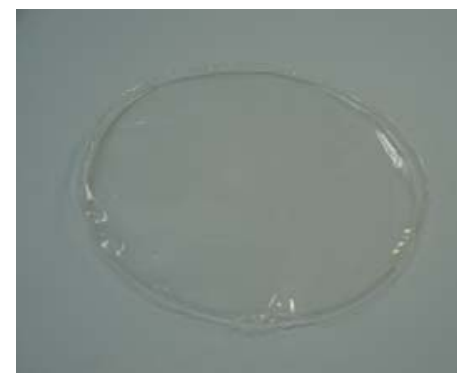

Figura 1 - Filme polimérico produzido.

\subsection{Ensaios das películas}

As propriedades físicas dos polímeros estão relacionadas à resistência das ligações covalentes, à rigidez dos segmentos na cadeia polimérica e à resistência das forças intermoleculares entre suas moléculas. Além da natureza química dos monômeros e do peso molecular dos polímeros, outro importante fator que afeta as propriedades do material é sua estrutura macromolecular. Do ponto de vista tecnológico, os materiais poliméricos devem 
apresentar resistência mecânica satisfatória (Mano et al., 1999). As propriedades da película polimérica determinam as características fundamentais do acabamento, como transparência, cor, flexibilidade, elasticidade, pegajosidade, resistência à tração, etc.

A partir da norma ASTM D 882 - Propriedades de tração de plásticos finos - foi elaborado o molde, a partir do qual as amostras foram cortadas (Figura 2 (a)). O filme foi desmoldado com auxílio de uma espátula e cortado de acordo com o molde adaptado para ensaio de tração de filmes poliméricos finos. Cada filme produzido gerou corpos de prova para tração (teste em triplicata para cada resina estudada) (Figura 2 (b)). Uma vez que a elongação do material é maior do que $100 \%$, a velocidade de ensaio configurada na máquina de tração foi de $500 \mathrm{~mm} / \mathrm{min}$ (Figura 2 (c)).
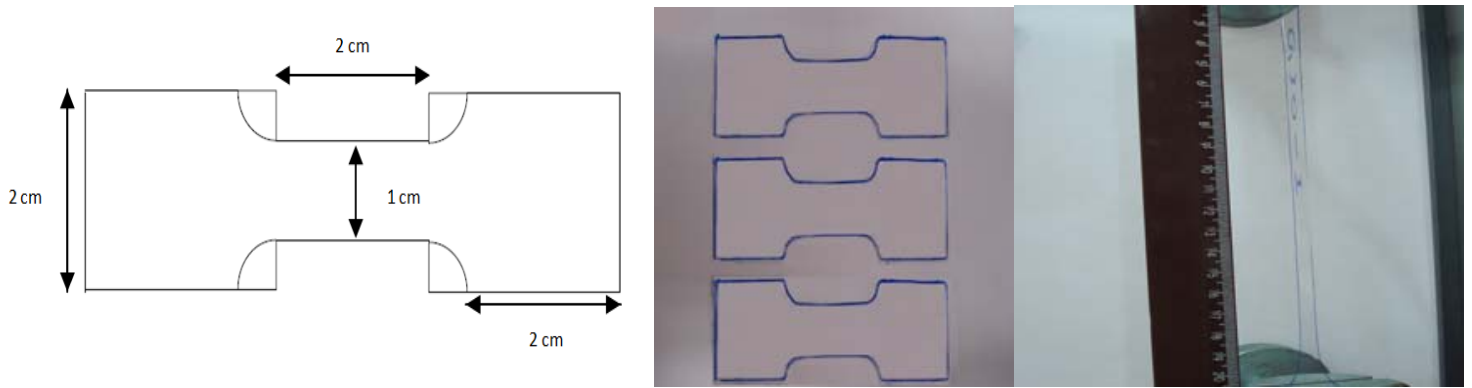

Figura 2 - (a) Molde utilizado para os corpos de prova dos filmes para ensaio de tração; (b) Filme cortado em triplicata; (c) Alongamento do filme no ensaio de tração.

Através dos valores obtidos nos gráficos de tensão versus deformação, a tenacidade da resina pode ser avaliada pelo cálculo da integral referente à área abaixo da curva.

\section{RESULTADOS E DISCUSSÃO}

A partir dos ensaios de tração, obtiveram-se os valores de tenacidade característicos para cada tipo de produto de acabamento/amostra (Figura 3), os valores máximos de tensão suportada (Figura 4) e as porcentagens de alongamento (Figura 5). Os gráficos foram separados de acordo com a natureza da resina (poliuretânica ou acrílica) e seu uso (camada base ou top).

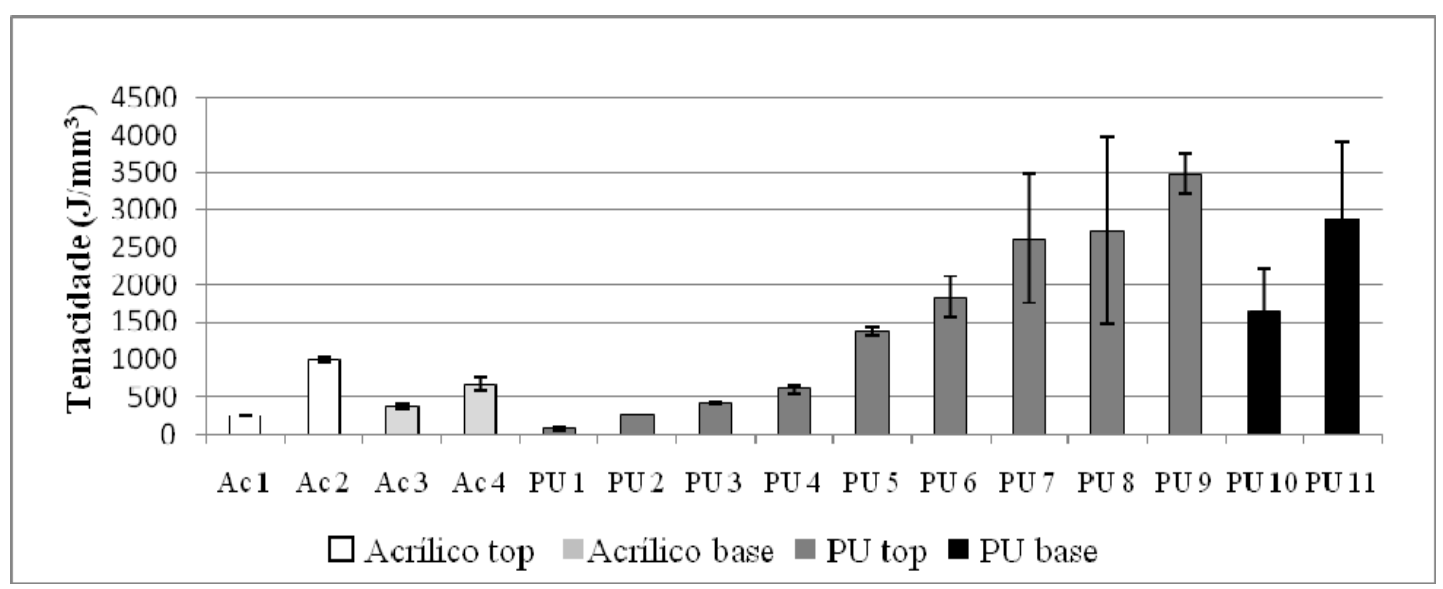

Figura 3 -Tenacidade dos filmes de resinas acrílicas e poliuretânicas testadas. 


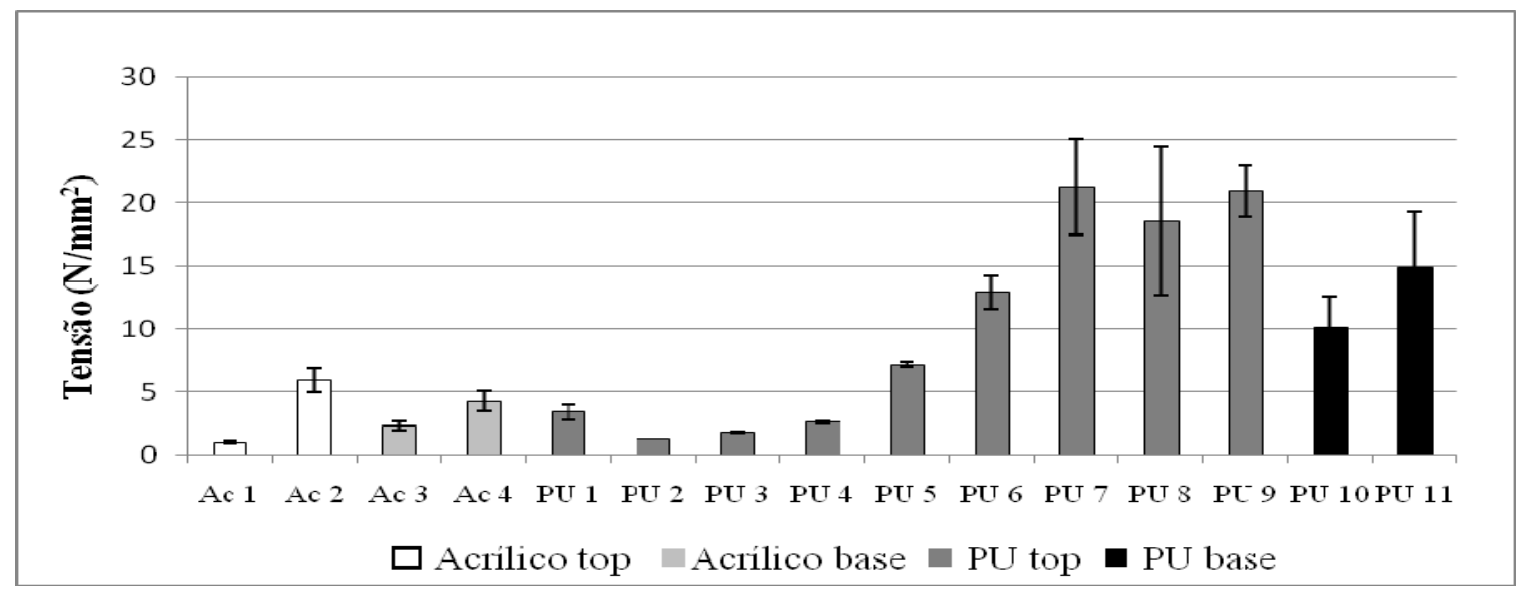

Figura 4- Valores máximos de tensão suportados pelas amostras.

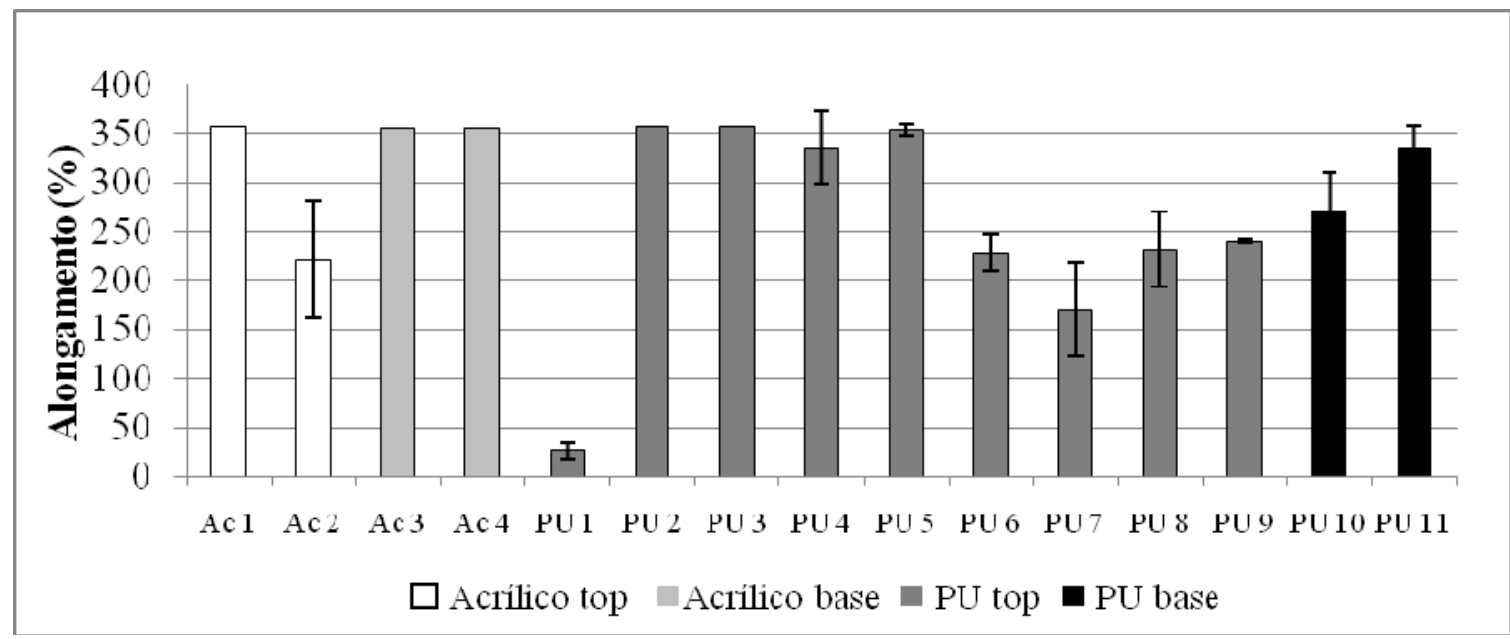

Figura 5 - Alongamento das amostras sob tração.

A análise da Figura 3 permite observar que os valores de tenacidade das amostras de filmes poliuretânicos são, em média, superiores aos acrílicos, ou seja, os filmes suportam um maior impacto para levar o material à ruptura. A Figura 4 também indica que a tensão suportada até o ponto de rompimento da amostra possui valores mais expressivos em amostras poliuretânicas. Já o alongamento (Figura 5) aparece mais alto nos testes referentes aos filmes acrílicos, chegando a valores em torno de 350\%. Tais valores correspondem ao limite da máquina de tração e, portanto, ao não rompimento desses filmes. As medidas de elongação se mostraram condizentes com as medidas de tensão, uma vez que os filmes de resinas acrílicas não suportam forças muito altas resultando em grandes alongamentos. A máquina de tração aplica na amostra uma força constante, sendo que a variável controlada no ensaio é a velocidade com que a amostra é tracionada. Comparando as resinas segundo sua aplicação como top ou base, não houve um comportamento distinto entre elas, uma vez que as amostras de ambas apresentaram comportamentos variados.

Com relação aos filmes compactos, resultantes de combinações de resinas para aprimoramento de exigências do setor, foram analisadas combinações, conforme mostrado na Figura 6. 


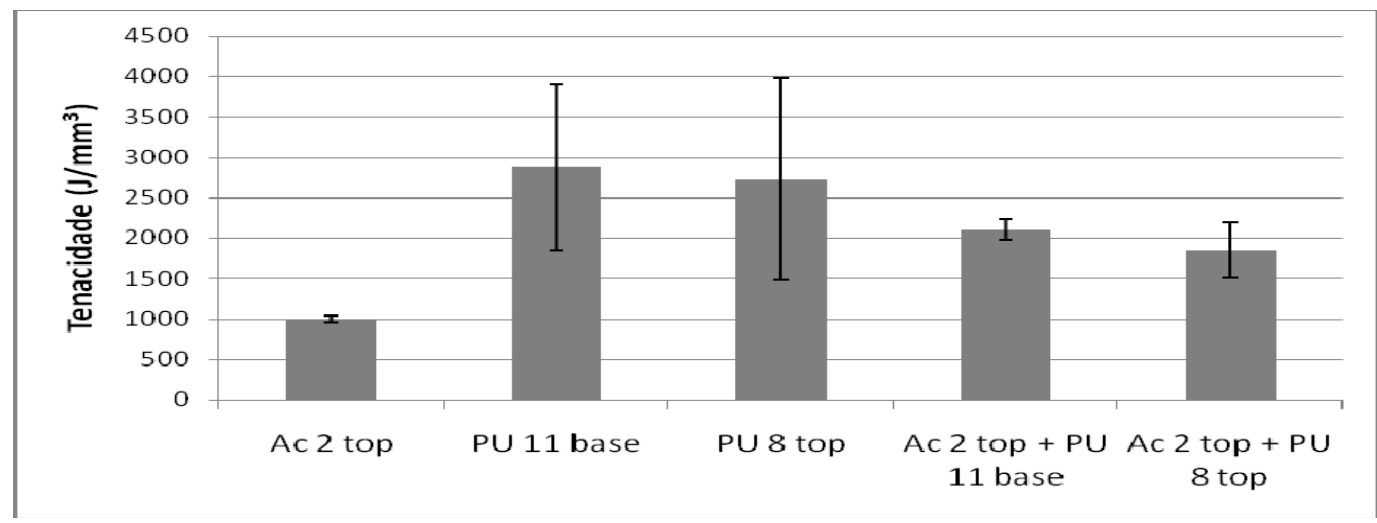

Figura 6 - Valores de tenacidade de filmes acrílicos, poliuretânicos e da sua combinação formando o compacto.

Conforme visto anteriormente, as propriedades de resinas acrílicas e poliuretânicas apresentam diferenças. Com a formulação de filmes compactos, nota-se que a combinação de resinas poliuretânicas diferentes (PU 11 base e PU 8 top) com a resina acrílica (Ac 2 top) melhora expressivamente seu valor de tenacidade. $\mathrm{O}$ valor obtido no compacto é intermediário ao valor dos filmes das respectivas resinas puras. A adição de resina PU na resina acrílica provoca um acréscimo considerável de tenacidade em relação à acrílica, ao mesmo tempo que a acrílica reduz esse valor em relação às PU puras. Análises de tensão e elongação apresentaram o mesmo comportamento, indicando que a produção de filmes compactos contribui para melhorias de propriedades em alguns tipos de resinas. $\mathrm{Na}$ combinação de outros compactos como, por exemplo, junção de duas resinas acrílicas base, os resultados de tenacidade, tensão e alongamento também foram intermediários (Figura 7).

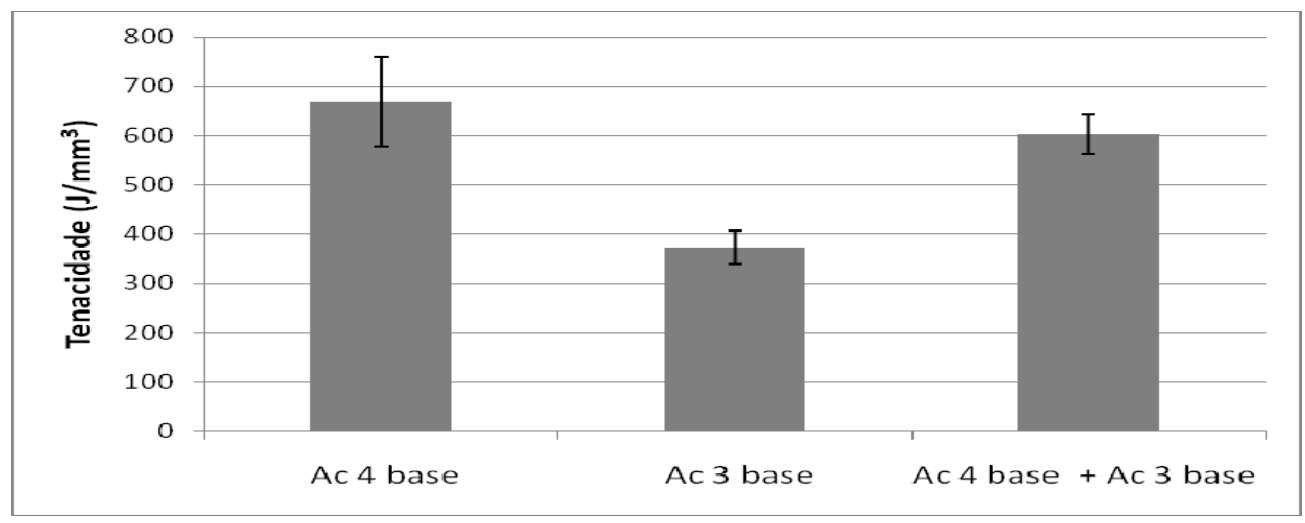

Figura 7 - Resinas acrílicas puras e seu compacto.

\section{CONCLUSÃO}

A partir da avaliação dos resultados obtidos e discutidos neste trabalho, pode-se concluir que das propriedades testadas, tensão, tenacidade e elongação, existem diferenças entre as resinas poliuretânicas e acrílicas. Os valores referentes às camadas top e base também apresentam divergências. Para suprir requisitos de produção de artigos, torna-se necessária a produção de filmes compactos, os quais aliam características próprias de cada resina, proporcionando inovação e aumento na gama de aplicação desses produtos, cobrindo, assim, 
maiores especificações. Tanto fatores econômicos, quanto tecnológicos e de inovação, buscam, na produção de compactos, a ampliação de possibilidades de uso, contribuindo para a qualidade final do artigo e para a satisfação de exigências do cliente.

\section{AGRADECIMENTOS}

Os autores agradecem o apoio financeiro da FAPERGS (edital 04/2012) - Programa Pesquisador Gaúcho (PqG) e à CAPES pela concessão da bolsa de mestrado.

\section{REFERÊNCIAS}

ABNT. Preparação do filme de ligantes. NBR 11033: 2 p. 2004.

ABNT. Determinação do teor de sólidos totais. NBR 11062: 2 p.2004.

ADZET, A. J. M.; BALLESTER, B. J., GRATACOS, M. E. Quimica-Tecnica de teneria. Igualada, Espanha: Editora Romanyà/Valls 1985.

AMORIN, M. C.; MELILLO, G. Poliuretano: Altíssima performance em acabamento de couros Setor Couro, v.22 p. 69-70, 1989.

ASTM. Standard test method for tensile properties of thin plastic sheeting. D882: 10 p. 2002.

BARBOSA JR, V.; RAMIRES, E.C.; RAZERA, I. A. T; FROLLINI, E. Biobased composites from tannin-phenolic polymers reinforced with coir fibers Ind. Crop. Prod., v. 32 p. 305-312, 2010.

FAZANO, C. A. T. V. Tintas - Métodos de controle de pinturas e superfícies. São Paulo: Hemus Editora Ltda, 1995.

GRATACOS, E.; BOLEDA, J.; PORTAVELLA, M.; ADZET, J. M.; LLUCH, G. Tecnologia quimica del cuero Barcelona, 1962.

HENKEL S. A. Indústrias químicas - Curso extraordinário de tecnologia do couro. Estância Velha, RS, 1986.

JING, H.; JIANZHONG, M.; WEIJUN, D. Properties of acrylic resin/nano-SiO2 leather finiching agent prepared via emulsifier-free emulsion polymerization. Mater. Lett., v. 62 p. 2931-2934, 2008a.

JING, H.; JIANZHONG, M.; WEIJUN, D. Synthesis of alkali-soluble copolymer (butyl acrylate/acrylic acid) and its application in leather finishing agent. Eur. Polym. Journal, v. 44 p. 26952701, 2008b.

KOZAKIEWICZ, J. Polysiloxaneurethanes: new polymers for potential coating applications Progress in Organic Coatings, v. 27 p. 123-131, 1996.

MANO, E. B. Polímeros como materiais de engenharia. São Paulo: Editora Blücher, 1991.

MANO, E. B.; MENDES, L. C. Introdução a Polímeros. São Paulo: Editora Blücher, 1999.

PIETRUCHA, K. Radiation grafting processes and properties of leathers modified with butyl acrylate Radiat. Phys. Chem, v. 19 p. 219-225, 1981.

SANTOS, S. S. dos.; GUTTERRES, M. KINDLEIN JR., W. Análises microscópicas de couros em etapas de acabamento. VI Congreso Internacional de Materiales - Colombia, 2011.

YILMAZ, O.; CHEABURU, C.N.; GÜLÜMSER, G.; VASILE, C. Rheological behaviour of acrylate/montmorillonite nanocomposite latexes and their application in leather finishing as binders Progress in Organic Coatings, v. 70 p. 52-58, 2011. 